\title{
Need Assessment of Stormwater Management Guidelines in Pokhara and Design of Stormwater Drains for Ward 2 of Pokhara, Nepal
}

\author{
Keshav Basnet ${ }^{1}$, Achyut Bhandari ${ }^{2 *}$, Kaushal Chandra GC ${ }^{3}$, Nirmal Baral ${ }^{4}$ and Netra Bahadur Katuwal ${ }^{5}$ \\ ${ }^{1}$ MSc Coordinator for Infrastructure Engineering and Management Program, Pashchimanchal Campus, Institute of Engineering, \\ Tribhuvan University, Nepal; \\ ${ }^{2} \mathrm{MS}$ student, Infrastructure Engineering and Management Program, Department of Civil and Geomatics Engineering, \\ Pashchimanchal Campus, Institute of Engineering, Tribhuvan University, Nepal; \\ ${ }^{1,3,4}$ Assitant Professor, Department of Civil and Geomatics Engineering, Pashchimanchal Campus, Institute of Engineering, \\ Tribhuvan University, Nepal \\ ${ }^{5} \mathrm{MS}$ student, State Key Laboratory of Information Engineering in Surveying, \\ Mapping and Remote Sensing, Wuhan University, China
}

\begin{abstract}
Frequent questioning by the publics and reports on newspaper about the failure of stormwater drainage infrastructure and new opportunity to develop environmental protection regulations at provincial level encouraged to study on the need assessment for stormwater management guidelines in Pokhara city of Nepal. Analysis for the necessity of such guidelines was performed through different perspectives like quantity of runoff, failure of infrastructure services due to unmanaged drains, problems faced by the planners due to lack to integrated design and so on. In the study, the existing infrastructures were seen to be undersized in many areas, water being discharge to natural bodies were below the international practices and their standards and lack of defined polices and regulatory bodies for design, construction and operation escalated these types of social problems in the community. Similarly, the basic steps for estimating the storm runoff of the selected catchment and determining the size of stormwater drains has been discussed that aids to design of road side drains. Finally, rectangular stormwater drains are designed based on detailed hydrological study for Ward 2 of Pokhara city in Nepal. The need assessment study along with design examples to solve pragmatic challenges plays an important contribution to government authorities in Pokhara City as well as Gandaki Province to formulate guidelines for stormwater management.
\end{abstract}

Keywords:- Flooding, Overflow, Road side drain, Flood management, Stormwater drain.

\section{INTRODUCTION}

A needs assessment is a systematic approach of studying the state of knowledge, ability, interest, or attitude of a defined audience or group involving a particular subject. The goal of the assessment is to specify what gaps exist, the cost of filling them, and which ones require immediate attention. Stormwater is water from rain and melting snow and ice. Stormwater management is the control and use of stormwater runoff. Stormwater management guidelines provides guidance in the planning and design of stormwater management infrastructure for developers, consultants, municipalities, and landowners and outlines the processes and infrastructure needed to address flooding, water quality, erosion, water balance, and natural heritage.

Pokhara area is selected for the study that lies inside the premises of the Gandaki Province. Political categorization of Nepal into urban cities (municipalities and metropolitan cities) and rural areas (Rural Municipalities), shown in Figure 1, tends to address the pace of urbanization in different parts of the country. As the impact of stormwater is seen higher in the places with huge change in infiltration rate and capacity and development of other physical infrastructures, Pokhara metropolis is chose as a major area for assessment due to its urbanization trend and high pace of development. 
ISSN No:-2456-2165

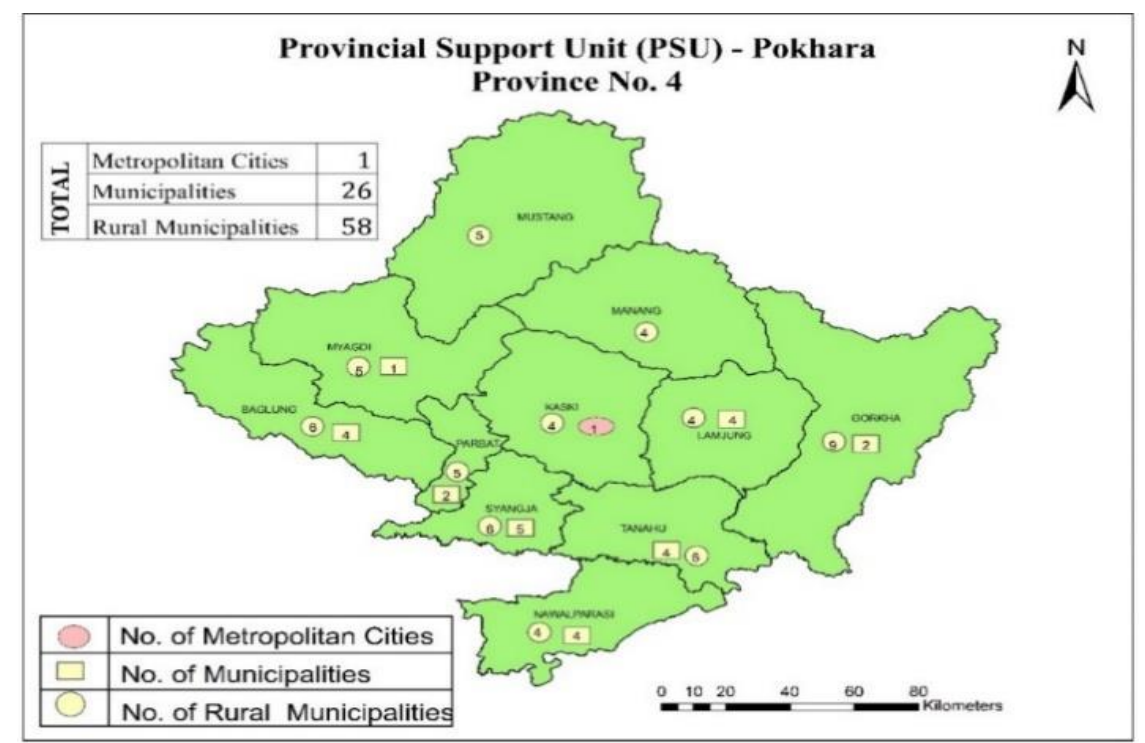

Fig 1:- Municipalities and Rural Municipalities in Gandaki Province, Nepal (Source: LGCDP, 2019)

After the study of the past design procedures, international practices, national design guidelines for different adjoining infrastructures like roads, canals, etc., a basic design steps for the construction of stormwater drain is suggested for Pokhara area in a set of solution examples corresponding to the issues facing by government engineers in the lack of proper guidelines. Furthermore drain size for storm water drains based on those example solutions were designed in this study and presented for Ward 2 of Pokhara.

\section{METHODOLOGY}

A need assessment is the through study of the requirement of something as per the clients from different possible viewpoints and its careful analysis. After studying the various guidelines from different cities from different countries of the world, it was concluded that the proper management guidelines determine the main principle on the stormwater, then describes about the quantity of runoff discharge, minimum quality of the water before its disposal, design ideology of the infrastructural components and its operation strategies. Based on the same findings, this study firstly analyzed about various approaches in developed cities. Then the overview study of the catchment was conducted followed by the present condition of quality and quantity of runoff in different parts of Pokhara during rainfall period. Similarly, the social need for the guidelines and its scope was studied and then the brainstorming was done considering all the internal and external factors for the requirement of the stormwater management guidelines in the area like Pokhara valley of the Gandaki province, Nepal.

Similarly, based on the existing studies and interdisciplinary national guidelines, a basic approach to estimate and design stormwater was studied with the base study from the different guidelines of the developed countries.

\section{OBSERVATIONS AND FINDINGS}

\section{A. Scenario Analysis \\ $>$ Practice Around the World}

Chang et. al (2018) in their studies on low impact development analysis for storm water management in urban cities concluded the western communities paid more attention to restore water quality while the eastern communities prioritized on flood prevention and rainwater harvesting. In USA two types of measures are in use for stormwater control viz., nonstructural and structural control measures. The Clean Water Act (1987) and its following supporting regulation and programs made various provisions to collect the stormwater separately, and discharge it to the water bodies only after the proper treatment and removal of the impurities. However, the act in Australia focus on discharge of the stormwater from the cities to the nearby water courses as soon as possible. Chang et. al (2018) also concluded that governments who took proactive and aggressive measures, whether through policies, regulations, or incentives, proved to be the most successful and are facilitating the shift from gray cities to green cities. (Committee on Reducing Stormwater Discharge Contributions to Water Pollution, 2008; Environment and Communications References Committee, 2015).

\section{Study of Catchment}

In Gandaki Province, there are total 27 municipalities and 58 rural municipalities covering the total area of 21,733 sq. km. (14.66\% area of country). Political categorization of Nepal into urban cities (municipalities and metropolitan cities) and rural areas (rural municipalities) tends to address the pace of urbanization in different parts of the country. The problems related to stormwater management is seen directly proportional to the pace of urbanization and the rate of change of land use patterns. 


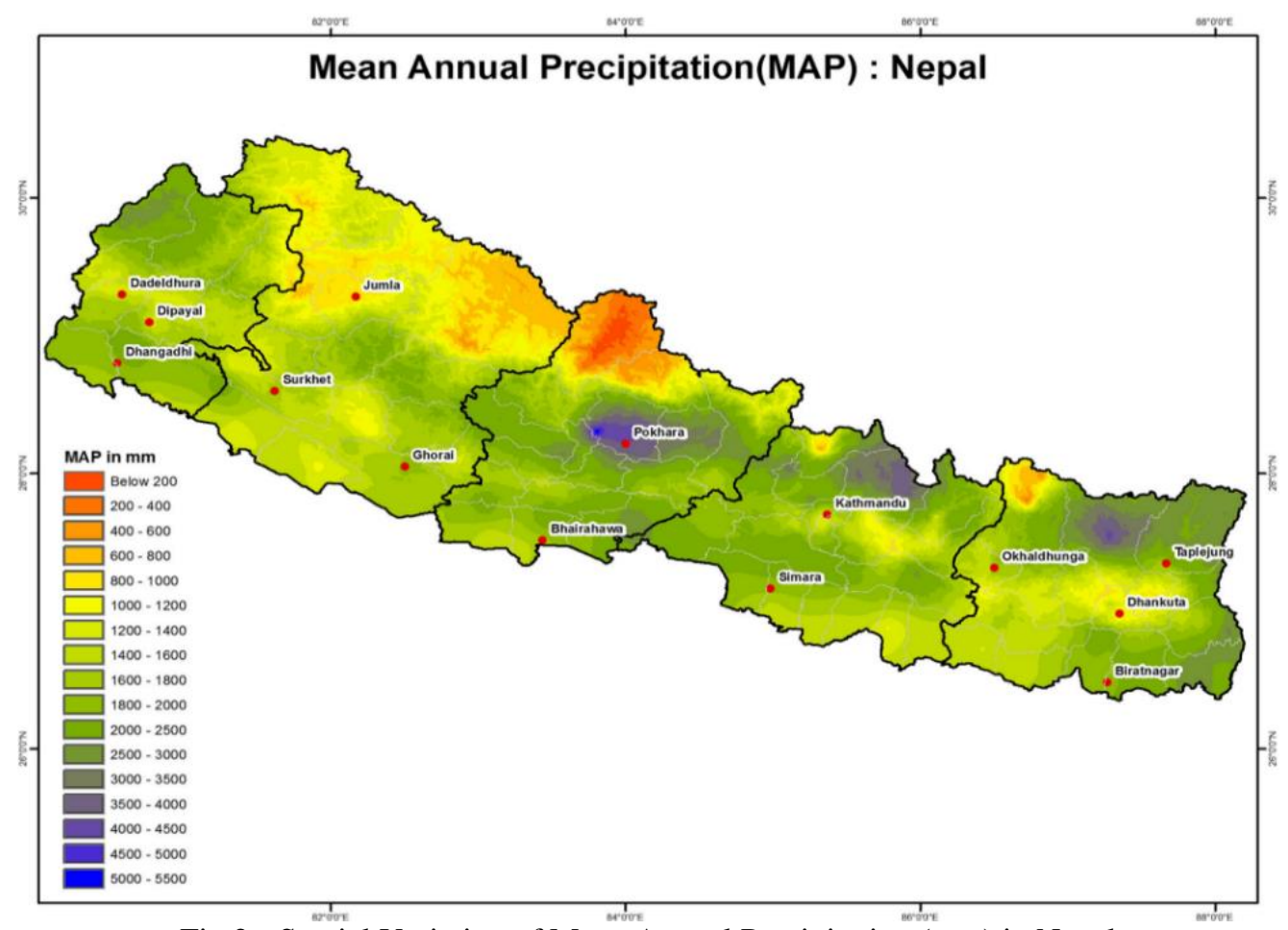

Fig 2:- Spatial Variation of Mean Annual Precipitation (mm) in Nepal (Source: Karki et. al, 2015)

Spatial variation of mean annual precipitation across the county is presented in Figure 2. Nepal, in a year, receives about $1,500 \mathrm{~mm}$ of rainfall in a good monsoon regime as per the record of Department of Hydrology and Meteorology. Rainfall is concentrated, and more than $75 \%$ of the annual rainfall occurs during the monsoon months beginning June through September. Weather and meteorological studies along with Department of Hydrology and Meteorology of Nepal has concluded the extreme events are mostly seen in the Pokhara valley at Lumle station, along with the highest mean annual precipitation in the whole nation. Being the Pokhara valley, a major city in the Gandaki Province, dealing with the issues of stormwater management and high pace of urbanization in the region, it is considered as the main study area for the research purpose.

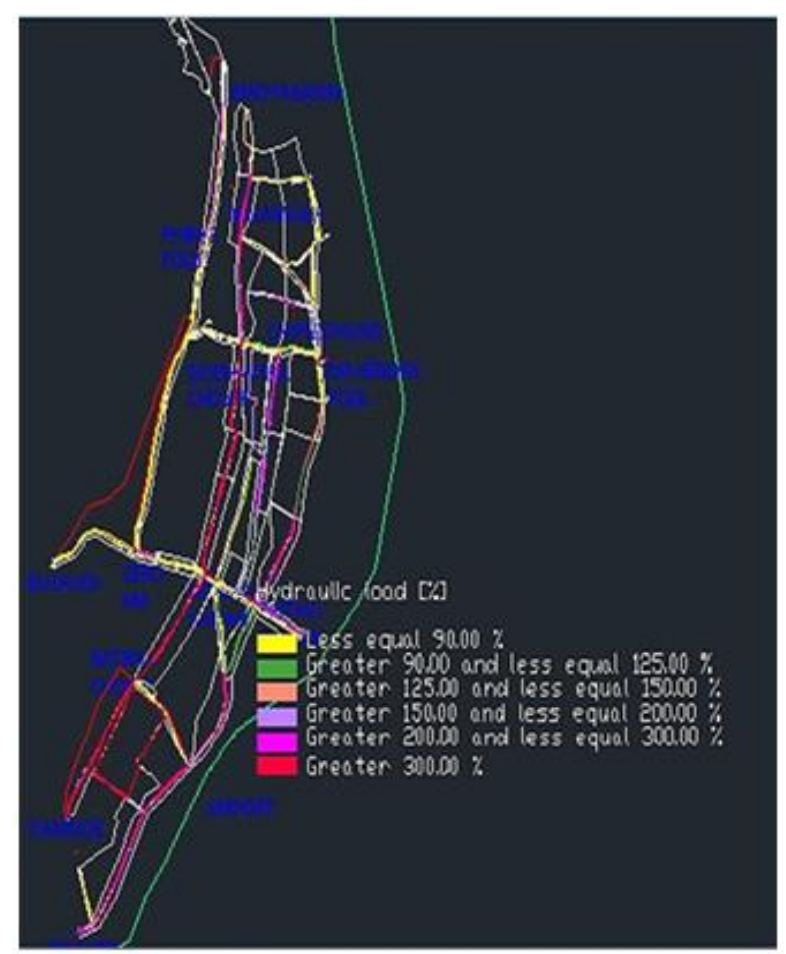

Fig 3:- Grade of Hydraulic Load of the Drainage Conduit in Existing Condition (Source: Basnet et. al, 2020) 


\section{Quantity of Stormwater}

High change in land use pattern can be seen in the Pokhara valley, due to high pace of urbanization. with the increase in urbanized area and the city of high mean annual rainfall, the problems related to the runoff management has been seen numerous times in the Pokhara valley. Various studies have been done to suggest the appropriate changes required to accommodate the runoff in that sub catchment. The existing drainage network was designed and constructed by the Pokhara Municipality Office in 1998 with the financial aid from Asian Development Bank. Basnet et. al (2020) studied about the stormwater drainage system for major area of Pokhara and analyzed about the existing infrastructures and its load factor in various network inside the city area. Figure 3 shows the loading factor calculated from the modelling of the catchment with their actual sizes of the drains in the given network.
The analysis shows that $80 \%$ of the catchment area is covered by impervious surface that includes the surface area covered by roads, residential and commercial buildings, etc. With increase in the impervious area and the frequency of the extreme precipitation events happening in the area, this loading factor are supposed to rise further.

\section{Social Need for the Guidelines}

Environment Protection Act, 2053 has been terminated and with the termination of the act, Environment Protection Rules, 2054 has also to be re-formulated to cope with the new act. The central act Environment Protection Act, 2076 has been formulated with the clear distinction on decentration of the power to the federal level government. The upcoming federal rules and regulations for environment protection is being drafted on many levels.

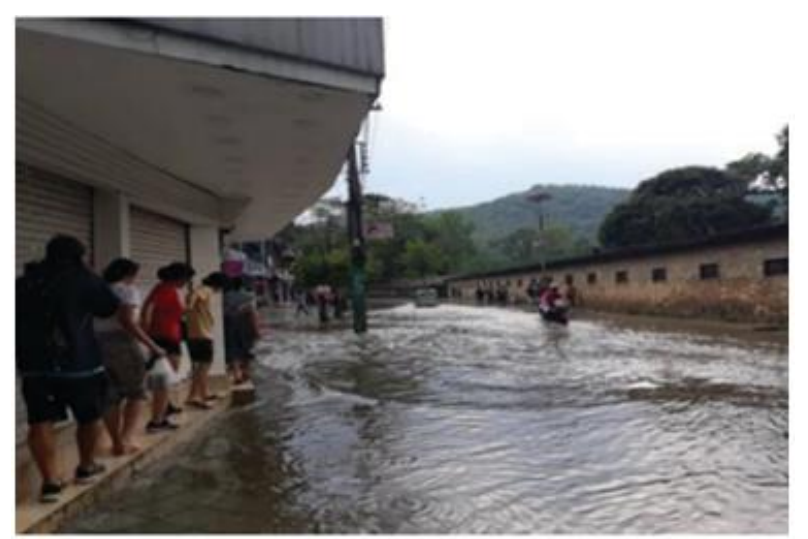

Fig 4:- Overflow on a Road of Lakeside, Pokhara During Heavy Rainfall

(Source: Khadka \& Basnet, 2019)

Similarly, the unmanaged and unplanned drainage network can be seen in the different parts in the valley. An example of the overflow problem can be seen in Figure 4. The main reason for such consequences is consider due to the lack of integrated master plan for the city drainage network and lack of guidelines. Planners and engineers have been working on their own knowledge without proper inter communication between different places that have caused the social problems like failure of transportation facilities and sidewalks, over topping of water from the drainage system on road pavements and hence affecting the aesthetic beauty of the cityscape. Sometime the news also has been reported of human casualties and death due to the high runoff of stormwater overtopping in the road pavement.

\section{B. Drainage Design \\ > Major Principle Adopted}

Best to aim to transport the stormwater as rapidly as possible from our urban areas to the nearest waterways. The best way to control the pollution in the runoff is to check the pollutants at the point source. The quantity of the of runoff can be determined by the Rational formula; $Q=C i A$,

where, $\mathrm{Q}$ is the peak surface runoff rate from a watershed in $\mathrm{m}^{3} / \mathrm{sec}, \mathrm{C}$ is the runoff coefficient at the surface of the catchment, $\mathrm{A}$ is the area of catchment in hectares, and $\mathrm{i}$ is the intensity of rainfall storm in $\mathrm{mm} / \mathrm{hr}$.

\section{$>$ Study of Catchment and Area of Drainage}

Digital elevation model made through the GIS software are very effective for determining the flow network of the area. If the model is not available than the topographical map with high precision can be used. For an urban location, a map that illustrates existing physical infrastructures is recommended as it helps to identify the existing drainage system as well as locations for major drains and cross drainages. Firstly, the overall area is scanned to layout the major drainage network and the cross drainages such to drain the stormwater to the natural bodies as fast as possible. 


\section{Example 1: Illustrating the Method of}

Determining Area of Drainage.

Problem: A Stormwater drain is to be constructed in Srijanachowk of Pokhara valley. Determine the area of catchment to be considered to calculate the storm runoff in that area.

Solution:

The topographic map of a given area can be obtained either from direct detail survey, or survey department or from the open street mapping software like google maps. The area considered is highly urbanized so the existing infrastructures and network need to be considered to plan the new drainage system. After the recce

of the Pokhara, the major drainage network of the valley was noted such that the area of catchment can be determined. The catchment area of the given location i.e., Srijanachowk is determined as follow.

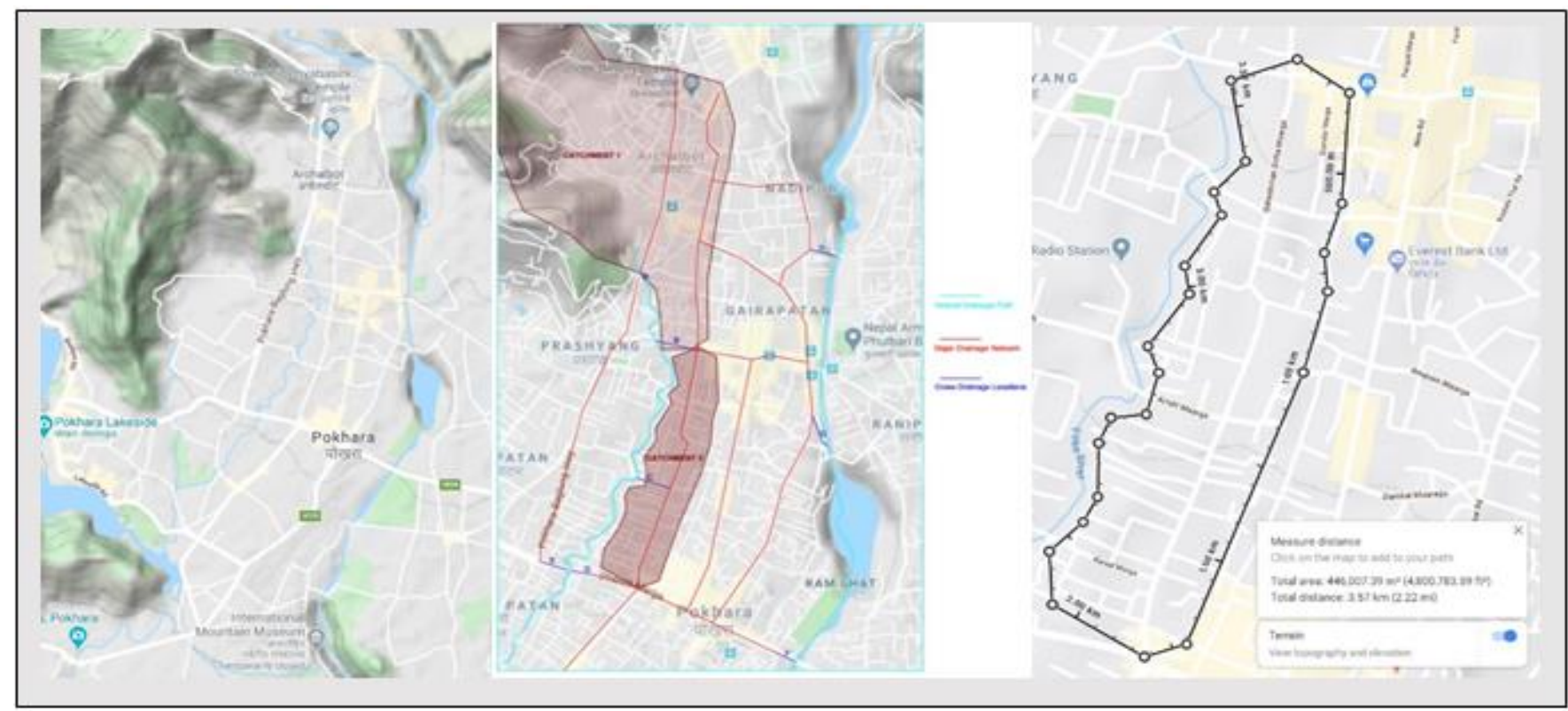


Here, the blue paths show the natural drainage paths that flows as the streams and the lines traced on the map represents the major road networks of the area. The area of the catchment is determined using graph area method. The area of the catchment at the outfall (Srijana Chowk) is $446,007.39 \mathrm{~m}^{2}$. The length of the drain to be constructed is $1530 \mathrm{~m}$ and the difference is attitude is measured to be $47 \mathrm{~m}$ on the opposite points of the drain.

\section{Coefficient of Runoff}

Coefficient of runoff defines the fraction of precipitation that has been converted to the surface runoff. Different land surfaces with different land cover have different coefficients. The land use map of the aera is to be obtained from the Survey Department. The mutual coordination between survey department, local government planning commission, and its executive brings the best updated map of land use land cover (LULC) map of the given locality at the given time. The coefficients from Table 1 can be used as considering design criteria.

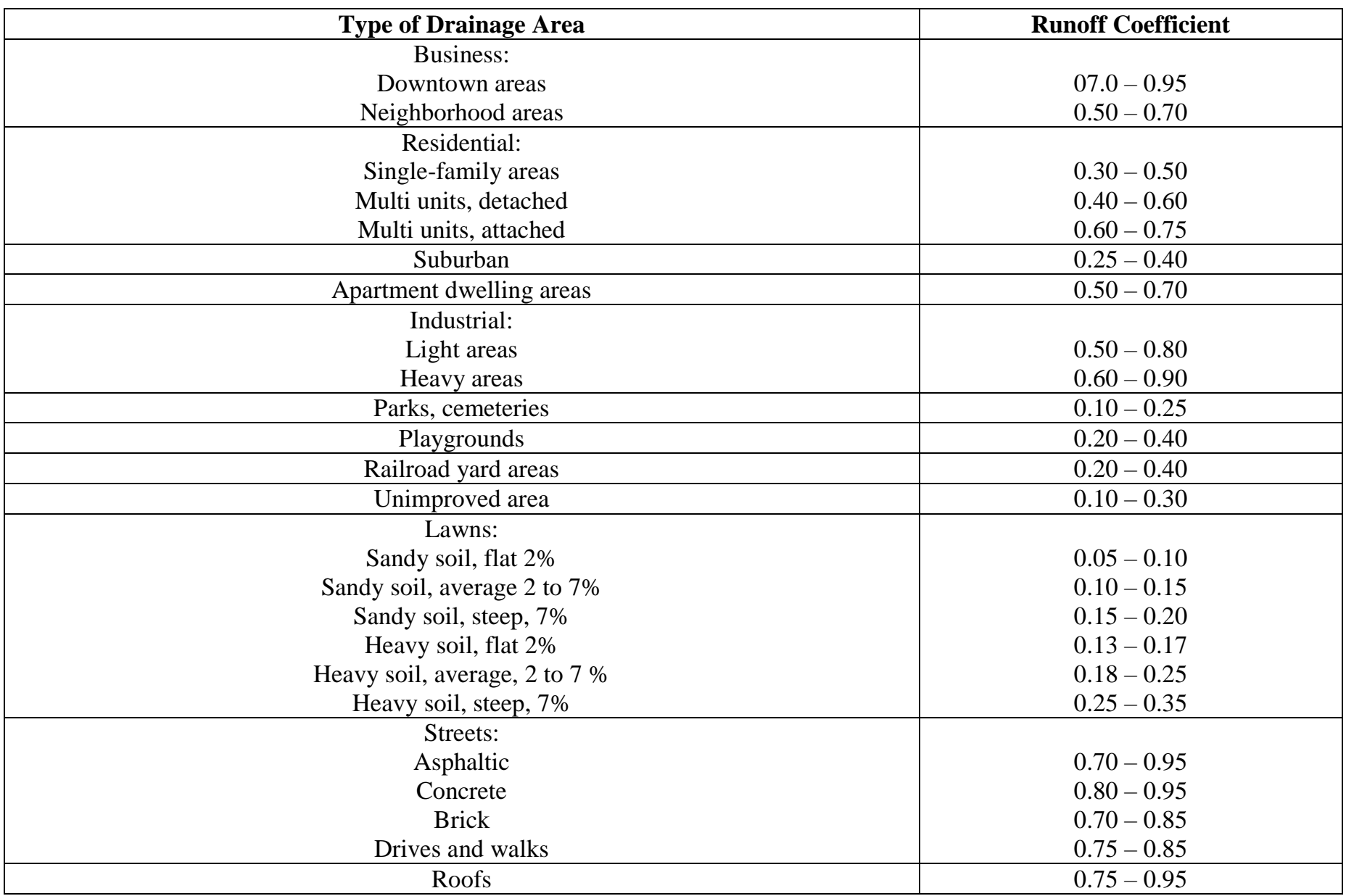

Table 1:- Runoff Coefficients in Urban Areas

Source:(Water Security Agency, 2014) 


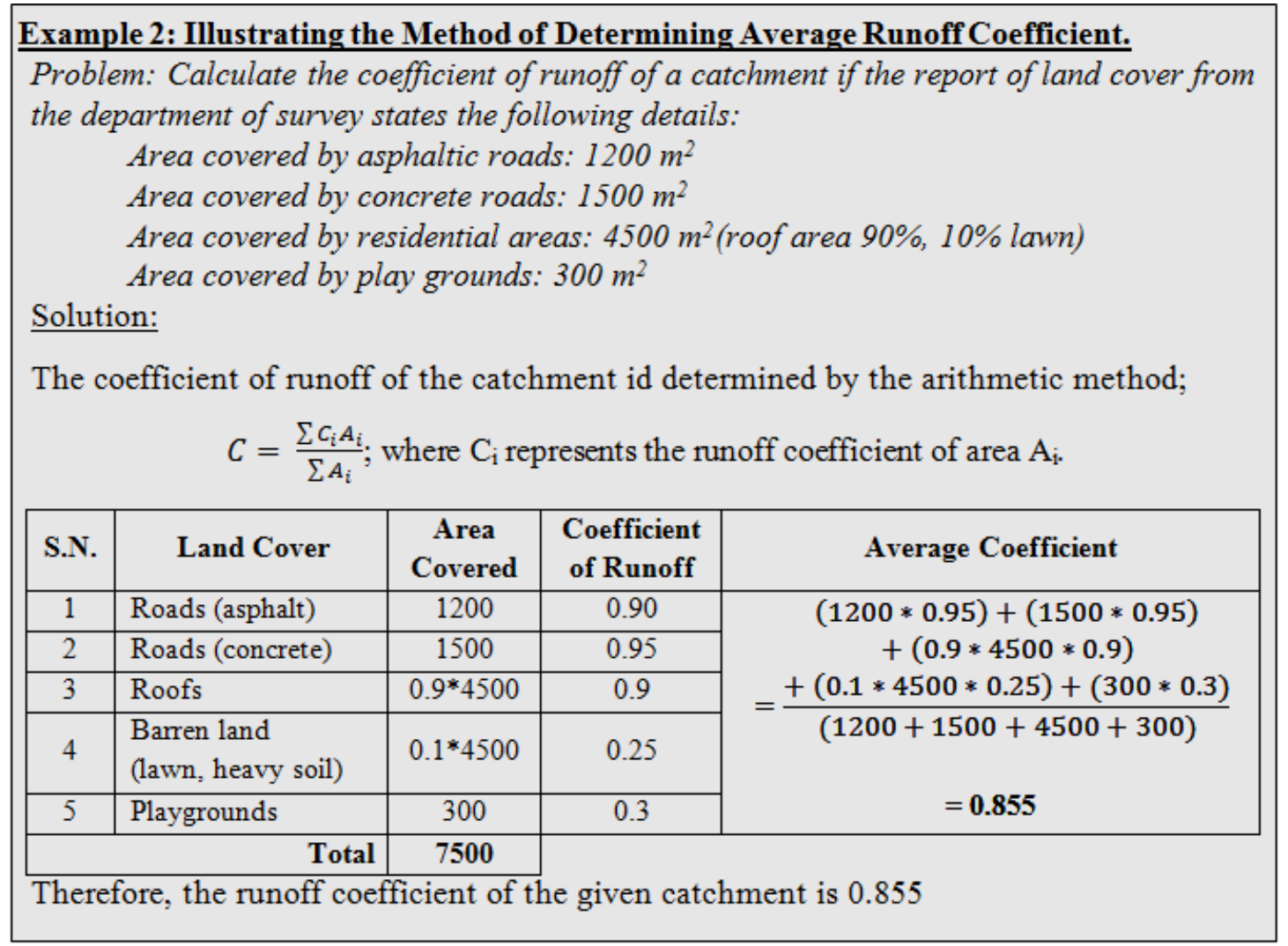

\section{Intensity of Rainfall}

Intensity of rainfall used to estimate the quantity of runoff is the major interpretation of the maximum rainfall the area might receive for the given design period. It is the probabilistic approach and is predicted through the past records. The time period for selecting intensity defines the importance of the infrastructure also. The department of roads in its Nepal Road Standards, 2070 has clearly stated that the return period for different types of road has to be adopted as per their recommendation while constructing the road drains on either side of the roads as shown in Table 2.

\begin{tabular}{|c|c|c|c|}
\hline Road Class & I and II & III & IV \\
$\begin{array}{c}\text { Return Period } \\
\text { (In Years) }\end{array}$ & 50 & 33 & 25 \\
\hline
\end{tabular}

Table 2:- Return Periods for Calculating Design Discharges Source:(Department of Roads, 2013)

To address the overall catchment of the Nepal, an empirical formula for the design intensity for different meteorological locations of Nepal was suggested as;

$\mathrm{I}_{\mathrm{hr}}=0.38 * \mathrm{H}_{24-\mathrm{hr} \max .} / 60(\mathrm{~mm} / \mathrm{min})$

The tabular format of the hourly rainfall design intensity for different return period of storm in major places of Gandaki province is presented in Table 3.

\begin{tabular}{|c|c|c|c|c|c|c|}
\hline \multirow{2}{*}{ Index No. } & \multirow{2}{*}{ Name of Station } & \multicolumn{4}{|c|}{ Return Period (Years) } \\
\cline { 3 - 7 } & Jomsom & $\mathbf{3 0 0}$ & $\mathbf{1 0 0}$ & $\mathbf{5 0}$ & $\mathbf{3 3}$ & $\mathbf{1 0}$ \\
\hline 0601 & Thakmarpha & 0.79 & 0.70 & 0.65 & 0.61 & 0.48 \\
\hline 0604 & Baglung & 0.80 & 0.70 & 0.63 & 0.58 & 0.42 \\
\hline 0605 & Tatopani & 0.94 & 0.89 & 0.86 & 0.83 & 0.75 \\
\hline 0606 & Lete & 0.98 & 0.87 & 0.81 & 0.77 & 0.62 \\
\hline 0607 & Beni Bazar & 1.29 & 1.14 & 1.03 & 0.95 & 0.71 \\
\hline 0609 & Ridi Bazar & 2.13 & 1.84 & 1.67 & 1.58 & 1.22 \\
\hline 0701 & Tansen & 2.98 & 2.44 & 2.12 & 1.90 & 1.17 \\
\hline 0702 & Musikot & 2.53 & 2.19 & 1.98 & 1.84 & 1.34 \\
\hline 0722 & Jagat (Setibas) & 1.25 & 1.06 & 0.96 & 0.90 & 0.68 \\
\hline 0801 & & & & 0.86 & 0.77 & 0.72 \\
\hline
\end{tabular}


ISSN No:-2456-2165

\begin{tabular}{|c|c|c|c|c|c|c|}
\hline 0802 & Khudi Bazar & 2.47 & 2.22 & 2.04 & 1.19 & 1.55 \\
\hline 0804 & Pokhara Airport & 2.64 & 2.31 & 2.12 & 1.93 & 1.49 \\
\hline 0807 & Kuncha & 2.85 & 2.41 & 2.12 & 1.90 & 1.30 \\
\hline 0808 & Bandipur & 3.01 & 2.50 & 2.17 & 1.94 & 1.34 \\
\hline 0809 & Gorkha & 2.91 & 2.31 & 1.94 & 1.66 & 1.01 \\
\hline 0810 & Chapkot & 2.98 & 2.53 & 2.31 & 2.14 & 1.58 \\
\hline 0811 & Malepatan Pokhara & 2.29 & 2.09 & 1.96 & 1.87 & 1.58 \\
\hline 0814 & Lumle & 2.28 & 2.06 & 1.96 & 1.85 & 1.58 \\
\hline
\end{tabular}

Table 3:- Estimated Values of Hourly Rainfall Design Intensity in $\mathrm{mm} / \mathrm{min}$

Source: (Jha, 2006)

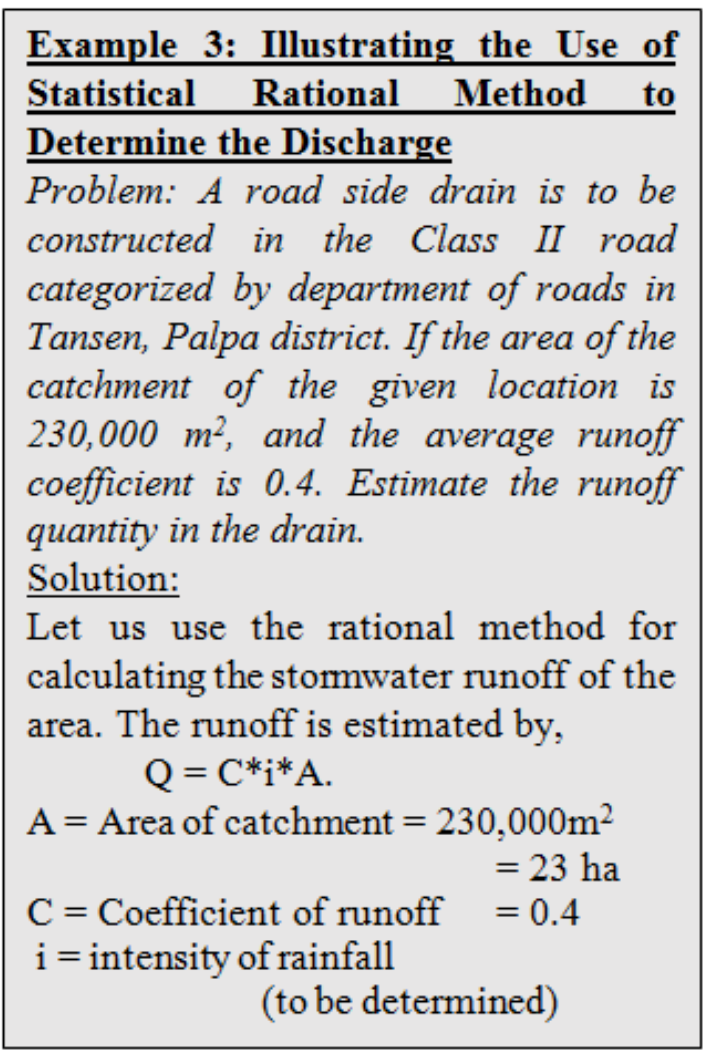

The road categorized by the department of roads is under class II, therefore the return period of storm considered is 50 years. (Refer Table 2)

The intensity of rainfall for 50 years of return period is $2.12 \mathrm{~mm} / \mathrm{min}$.

(Refer Table 3, Index no. 0702)

Intensity of rainfall (i) $=2.12 \mathrm{~mm} / \mathrm{min}$

$$
=127.2 \mathrm{~mm} / \mathrm{hr}
$$

$\mathrm{Q}=\frac{\mathrm{C} * \mathrm{i} * \mathrm{~A}}{360}=\frac{0.4 * 127.2 * 23}{360}=3.250 \mathrm{~m}^{3} / \mathrm{s}$.

Therefore, the design runoff quantity at Tansen is $3.250 \mathrm{~m}^{3} / \mathrm{s}$. 


\section{Sizing of the Drain}

Manning's formula is perhaps the most widely used empirical equation for estimating discharge since it relies solely on channel characteristics that are easily measured. Manning's formula is:

$$
Q=\frac{1}{n} A R^{\frac{2}{3}} S^{\frac{1}{2}}
$$

where,

$\mathrm{Q}=$ discharge $\left(\mathrm{m}^{3} / \mathrm{s}\right)$ through a drain

$\mathrm{A}=$ cross sectional area of the drain $\left(\mathrm{m}^{2}\right)$
$\mathrm{R}=$ hydraulic radius $(\mathrm{m})$, (area/wetted perimeter of the channel)

$\mathrm{S}=$ bed slope of the drain

$\mathrm{n}=$ Manning's roughness coefficient of the drain materials.

Roughness coefficient depends upon the drain material used in lining. Recommend values of roughness coefficient for some major drain materials are resented in Table 4.

\begin{tabular}{|c|c|}
\hline Lining Type & Roughness (n) \\
\hline Dry stone & 0.025 \\
\hline Dry brick (without mortar) & 0.020 \\
\hline Dressed masonry & 0.018 \\
\hline Brick & 0.017 \\
\hline Random rubble & 0.020 \\
\hline Unreinforced concrete & 0.015 \\
\hline Shotcrete & 0.017 \\
\hline
\end{tabular}

Table 4:- Recommended Values of Roughness Coefficient Source:(PDSP Manual Volume M 8, 1990)

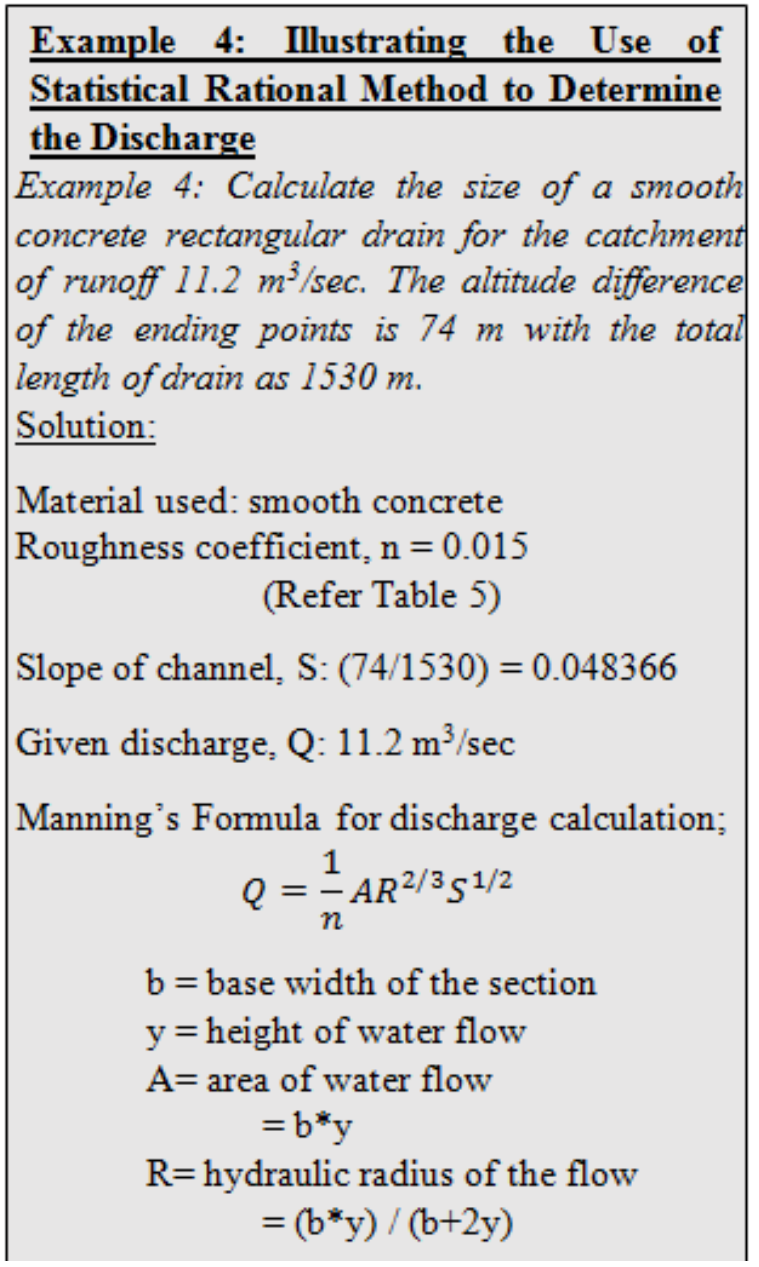




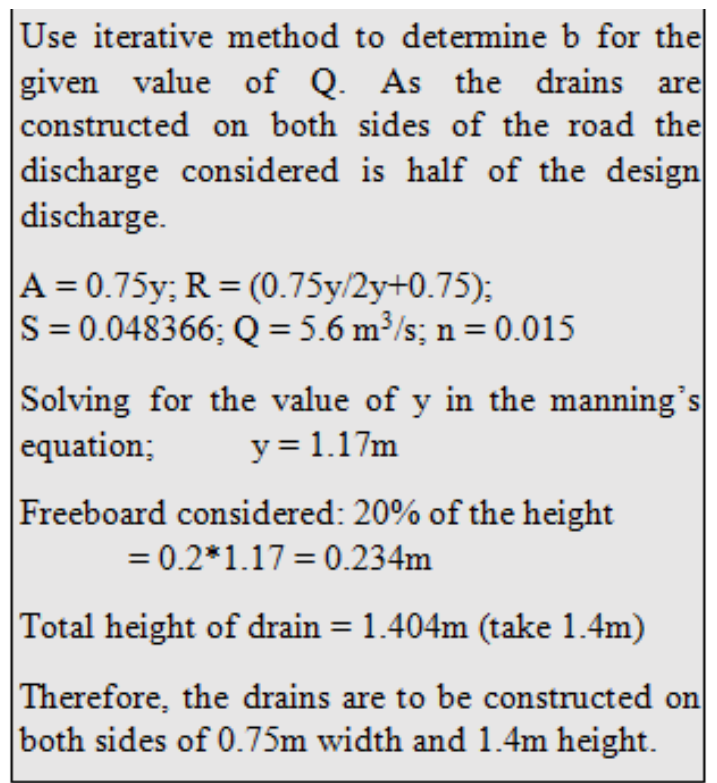

\section{RESULTS AND DISCUSSION}

The topography of the Gandaki province is vast as it covers plains of terai in south to mountains in north. The average precipitation of the area is also more compared to any other places of the nation. As the stormwater problems are seen on change in land use and infiltration capacity of the given place, adverse impacts are more seen on the urbanizing cities. In the study of Pokhara for the need assessment, the quantity of runoff in drains, and major problems created by the infrastructure failure were discussed.

In the major drainage network of the city, the water was from residential units and the quantity of runoff was low before any storm occurred. Then the existing drains could easily haul the given amount of water to the outfall locations. While the storm occurred, the quantity of runoff in the drains were high. Existing drains were heavily flooded by the rainwater. In the meantime, the drainage network failed. The runoff spilled over the roads and public places obstructed the traffic flow, pedestrians' path, aesthetic of the city.

Lack of any design procedures to estimate the quantity and determine the size of the drains has been prolonging the problems related to effective design in the developing cities. To address the problem, rational method can be used to determine the quantity of runoff and manning's' for calculating the required size of the drain. The variables that affect the designs as intensity of rainfall, land use of the catchment can be found from different organizations like meteorological department and survey department respectively. For calculating the size of drain, the manning's coefficient for the selected material can be used from standard norms.

\section{Drainage Design}

A drainage network is to be designed on Ward 2 of Pokhara Metropolis. Situated on the northern side of former
Pokhara Sub-Metropolitan, the area has about $65 \%$ of the total covered by manmade surface. The infrastructures built in the past has now either completely damaged or in the verse of collapse. The high runoff in the area has now started to arises the social problems like urban flooding in the settlement, obstruction of road network and adverse result in the aesthetic environment after the flooding declines. To address the problems, design of storm drain infrastructures is required.

Firstly, the major drainage network is studied that exists on the city area (Figure 5) and the possible outfalls are selected.

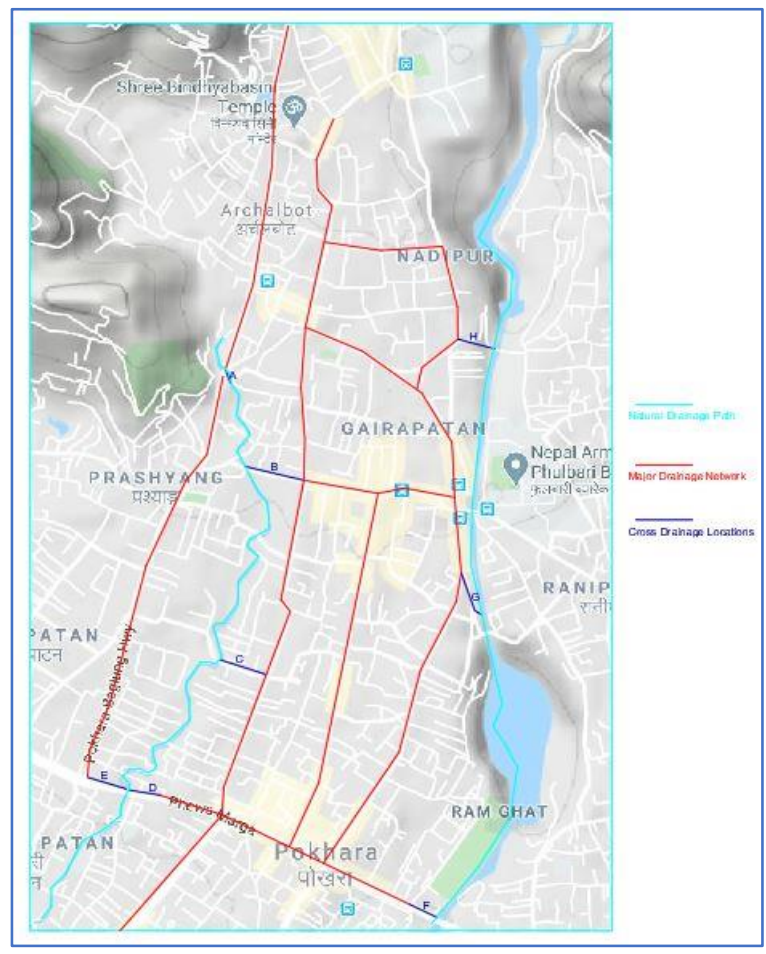

Fig 3:- Major Drainage Network of the City (Pokhara Metropolis) 
ISSN No:-2456-2165

The design area falls on the northern part of the city. After knowing the potential outfall location of the drains, the road networks and the existing drain where noted inside the design area as illustrated in Figure 6. Based on the recce and the topographical map of the design region, the subcatchments were delineated as shown in Figure 7.

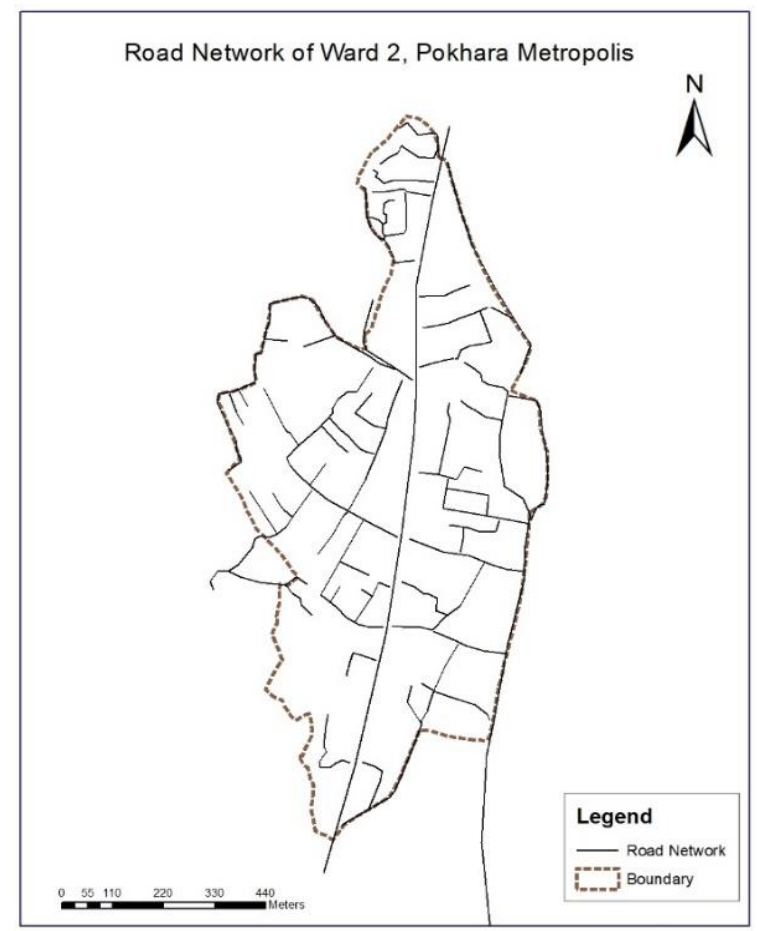

Fig 4:- Road Network of Design Area

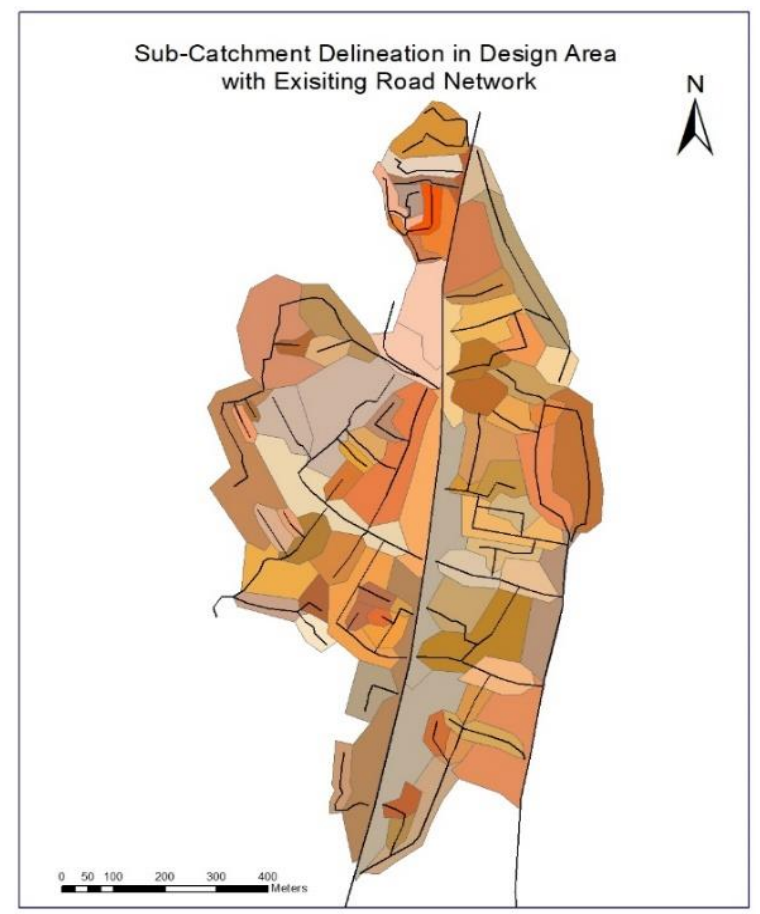

Fig 5:- Sub-Catchment Delineation of Design Area
After the land use map of the selected area is created and analyzed in Figure 8, it gives the runoff coefficient of the respective sub catchments. The drains linked with the road helps to determine the return period for the intensity of rainfall. After knowing the coefficient of runoff, intensity of rainfall and the area of sub catchments, the runoff of the respective sub catchments were calculated.

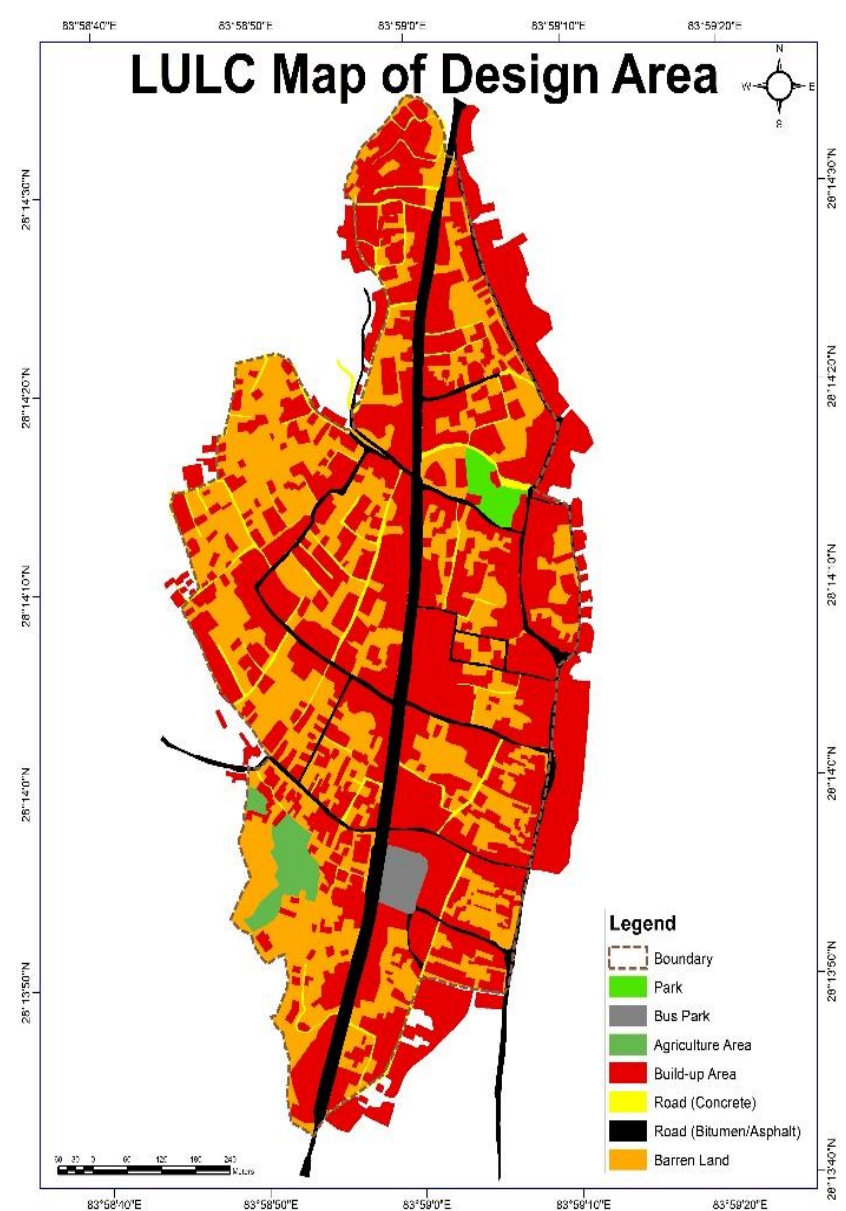

Fig 6:- Land Use Land Cover (LULC) Map of Design Area

In the study the whole catchment was divided into seven different regions. The area covered by each category based on landcover of the given catchment is shown in Table 5. 
ISSN No:-2456-2165

\begin{tabular}{|c|c|c|c|}
\hline S.N. & $\begin{array}{c}\text { Land Use / } \\
\text { Land Cover }\end{array}$ & $\begin{array}{c}\text { Area } \\
\text { (Sq. Mtrs.) }\end{array}$ & \% Covered \\
\hline 1 & Asphalt Road & 57561.54 & 8.35 \\
\hline 2 & Concrete Road & 23438.58 & 3.40 \\
\hline 3 & Built-Up Zone & 345447.21 & 50.14 \\
\hline 4 & Barren Land & 248890.9 & 36.12 \\
\hline 5 & Park & 6196 & 0.9 \\
\hline 6 & Agriculture Land & 881.19 & 0.13 \\
\hline 7 & Bus park & 6581.93 & 0.96 \\
\hline
\end{tabular}

Table 5:- Land Cover Details of Ward 2, Pokhara Metropolis

Based on the quantity of the runoff, the dimension for the drains to be constructed were calculated for the material used in construction as cement concrete. The plum concrete or RCC concrete drains can be construed in the regions as per their suitability. In the design process only the drains are designed, however all the streets need to have the catch drain in the road side to collect the rainwater from road and then contribute it to the nearest drainage network. In Figure 9, the labels on the drains describe the design drain width, height and the longitudinal slope of the given section for the drain in the drainage network.

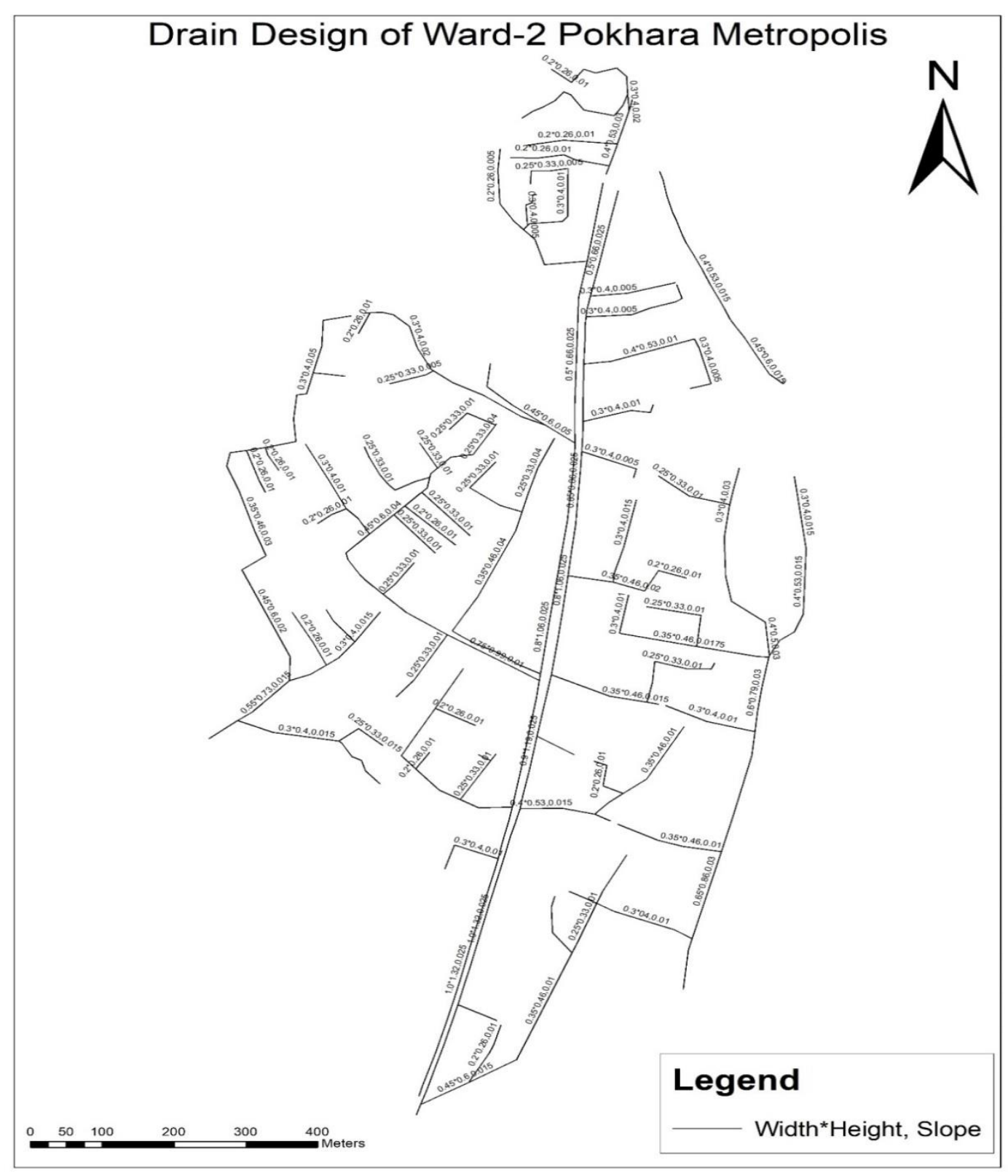

Fig 7:- Design Size of Stormwater Drains for Ward 2, Pokhara Metropolis 


\section{CONCLUSION}

In the assessment, the problems like unmanaged and inconceivable sizes of the drains, discharge of the grey water in the storm drain and lack of any regulatory and planning bodies were due to the lack of proper rules and guidelines. These problems are solved by proper designing of the storm drains. As no any procedures are formulated till the date, the design process of the storm drain network is difficult. In the study, the need for guidelines was performed for the whole city, Pokhara. The heavy hydraulic loading in existing drains and poor condition of the drains infrastructures shows the importance and necessity of the guiding rules. In the design of the storm drain network, Ward 2 was chosen for its heavy urbanization trend. The area was survey then after determining the area of drainage, intensity of rainfall and runoff coefficient of the area were calculated, the quantity of runoff was calculated. Based on the discharge on the sub-catchments the rectangular drains were designed for concrete surface with justified freeboard. Finally, the drain size required in the area was presented in the map form with the required width, height and longitudinal slope of the drain. In conclusion, this study stressed on the need of stormwater management guidelines for urban areas of Nepal like Pokhara while the methodology adopted here for designing stormwater drains and presented as design examples can be used by Pokhara City office and Gandaki Province office to start formulating the storm water management guidelines which is in extreme need for saving not only the roads but also the human life.

The method used to estimate the storm runoff is probabilistic in nature. To calculate the discharge with more accuracy, major two recommendations are; 1) the land cover of the area in a developing cites changes rapidly, to calculate the land cover and hence the coefficient of runoff, the trend analysis on land use land cover map need to be performed frequently, and 2) one need to consider the fact that the intensity of the rainfall differs spatially.

\section{ACKNOWLEDGEMENT}

Authors would like to thank the Pokhara Municipal Planning Commission and its members for the immense support in recce, survey and design process of drainage network in Ward 2, Pokhara Metropolis.

\section{REFERENCES}

[1]. Basnet, K. \& Neupane M. (2018). Storm water drainage design based on hydrological analysis: a case study on Lamachaur catchment area, Pokhara, Nepal. Oodbodhan: A Journal of TUTA, Pashchimanchal Campus.

[2]. Basnet, K., Baniya, U., and Karki, S. (2018). Comparative study of design discharge calculation approaches: a case study on Padhu Khola, Kaski, Nepal. Oodbodhan: A Journal of TUTA, Pashchimanchal Campus, 5 (5).
[3]. Basnet, K., Chhetri, K. B., \& Parajuli, G. (2020). Hydrological and hydraulic analyses of urban storm water drainage system of major area of Pokhara, Nepal. Preprint.

[4]. Chang, N. Bin, Lu, J. W., Chui, T. F. M., \& Hartshorn, N. (2018). Global policy analysis of low impact development for stormwater management in urban regions. Land Use Policy, 70(January), 368383. https://doi.org/10.1016/j.landusepol.2017.11.024

[5]. Committee on Reducing Stormwater Discharge Contributions to Water Pollution. (2008). Urban Stormwater Management in the United States. The National Academies Press. https://doi.org/10.17226/12465

[6]. Department of Roads. (2013). Nepal Road Standard 2070.

[7]. Environment and Communications References Committee. (2015). Stormwater Management in Australia. Retrieved from www.aph.gov.au/senate_ec

[8]. Jha, P. C. (2006). Estimation of Hourly Rainfall Design Intensity From 24 -hour Maximum Rainfall : The Context of Nepal, (March).

[9]. Karki, R., Talchabhadel, R., Aalto, J., \& Baidya, S. K. (2015). New Climatic Classification of Nepal. Theoretical and Applied Climatology, (July). https://doi.org/10.1007/s00704-015-1549-0

[10]. Khadka, S. \& Basnet, K. (2019). Storm Water Management of Barahi Chowk Area, Lakeside , Pokhara , Nepal using SWMM. KEC Conference, 2(1), 320-325.

[11]. LGCDP. (2019). Provincial Support Unit (PSU), Pokhara: Local Governance and Community Development Programme (LGCDP) - II. Retrieved from http://lgcdp.gov.np/pokhara

[12]. Neupane M., Basnet K., \& Parajuli, G. (2020). Modeling of urban storm water drainage using HYKAS for Lamachaur, Pokhara, Nepal. Proceedings of IOE Graduate Conference, Summer 2020.

[13]. PDSP Manual Volume M 8. (1990). Design Manuals for Irrigation Projects in Nepal.

[14]. Water Security Agency. Stormwater Guidelines (2014). Saskatchewan, Canada. 